\title{
CAMINOS RARÁMURI PARA SOSTENER O ACABAR EL MUNDO. TEORÍA ETNOGRÁFICA, CAMBIO CLIMÁTICO Y ANTROPOCENO ${ }^{12}$
}

\author{
Alejandro Fujigaki Lares ${ }^{1}$ \\ ${ }^{1}$ Instituto de Investigaciones Sociales, Universidad Nacional Autónoma de México
}

\section{Introducción}

En 1988, con el fin de facilitar las evaluaciones y los conocimientos integrales sobre el cambio climático, la Organización Meteorológica Mundial (OMM) y el Programa de las Naciones Unidas para el Medio Ambiente (PNUMA) fundó el Grupo Intergubernamental d Google Ateliê Digital: Fundamentos do Marketing DIgital e Expertos sobre el Cambio Climático (IPCC). En términos generales, el cambio climático (en adelante CC) es el proceso de alteración en la composición atmosférica mundial que ha intensificado la variabilidad del clima, sobre todo si se compara con la regularidad mantenida en los últimos 10 mil años. La principal causa es el calentamiento global provocado, directa e indirectamente, por agentes antropogénicos, particularmente por las altas emisiones y acumulaciones de gases de efecto invernadero (GEI), como el bióxido de carbono, el metano y el óxido nitroso. Los efectos -tales como el impacto en los ciclos hídricos y en los litorales, en la producción de alimentos y en la salud de los seres vivos- pueden medirse por el aumento y el descenso histórico de temperatura en el clima, en el aire, en los océanos, por una mayor desertificación y por la reducción en las cantidades de nieve y hielo, así como mediante el aumento de los niveles del mar, precipitaciones de lluvia, huracanes y tifones (IPCC 2013; ONU 2019; Centro Mario Molina 2019). El grado, la intensidad y la escala de esta alteración antropogénica en el planeta no tiene precedente. Este proceso ha provocado intensos debates en todas las áreas del conocimiento y de la política, así como el impulso de medidas económicas, sociales y políticas a nivel local, nacional e internacional (como el Protocolo de Kioto, 1995; el Acuerdo de París, 2015; la Cumbre 
del clima, 2019). Sin embargo, los resultados de estas acciones han sido insuficientes para revertir los efectos que constituyen, según la ONU, "el mayor desafío de nuestro tiempo".

El origen humano directo e indirecto de estas alteraciones o la "toxicidad antropogénica" (Povinelli 2016a, 2016b) ha sido objeto de múltiples debates científicos. Los estudios sobre el Antropoceno surgen en la geología y coinciden con algunos de los argumentos discutidos desde la meteorología sobre el CC en una escala sincrónica y diacrónica mayor. Existen cuantiosas discusiones y posturas dedicadas al Antropoceno. Pese a contar con planteamientos anteriores o alternos -tales como la conceptualización de Gaïa de James Lovelock y Lynn Margulis (Stengers 2014, Latour 2017) o las nociones de "fin del mundo", de tradiciones de amerindias y no amerindias (Danoswki y Viveiros de Castro 2014), así como de un debate heterogéneo que dio lugar a términos como Capitaloceno (Moore 2015; Ulloa 2017), Plantatioceno (Haraway et. al. 2016) y Chtutuluceno (Haraway 2016) - la noción de Antropoceno ha impactado a nivel global en todos los campos del conocimiento y de la política.

La oficialización de este término fue realizada por los geólogos Paul Crutzen y Eugene Stoermer (2000) y Crutzen (2002). Desde el 2009, el Grupo de Trabajo del Antropoceno (AWG por sus siglas en inglés) retomó esta noción para discutir sus implicaciones. En 2016, el Congreso Internacional de Geología reconoció al Antropoceno como una nueva época geológica y, en mayo de 2019, dicho panel de especialistas votó para definir al Antropoceno como "una unidad geológica de tiempo". A pesar del consenso, existen diversas posturas que debaten a fondo los conceptos, las técnicas, los lugares, los materiales y los momentos de medición que fundamentan este fenómeno (Anthropocene Working Group 2019; Subramanian 2019).

En términos generales, el Antropoceno se define como el intervalo de tiempo geológico en el cual el impacto humano alteró las condiciones y los procesos en la Tierra, intensificándose al inicio de la industrialización (Anthropocene Working Group 2019). Además de una categoría geológica (Trischler 2017), el concepto ha sido debatido desde la antropología, la historia, la sociología, la ciencia política, la filosofía, la economía, entre otras disciplinas, ${ }^{3}$ entendiendo dicho fenómeno como la huella tóxica de los humanos inscrita en la historia de la Tierra y en sus modos de existencia (humanos y no-humanos). En consecuencia, el campo de alteraciones que provoca el Antropoceno se ha ampliado analíticamente, sumando: el crecimiento dinámico de la población, la urbanización desbordada, el desarrollo intenso de la infraestructura, el consumo y su incremento, la explotación desenfrenada de recursos, la intensificación y la diversificación de la pobreza, así como la pérdida de la biodiversidad y la extinción masiva de especies 
(García Acosta 2017; AWG 2019).

El protagonismo de la toxicidad antropogénica (Povinelli 2016a, 2016b) replantea el análisis de las relaciones entre los humanos y los diferentes entornos a lo largo de la historia. El reconocimiento de estas afecciones antropogénicas puede resultar una obviedad. Sin embargo, el cambio de escala de este proceso nos obliga a replantear esta afirmación como una premisa. Principalmente por la posición jerárquica de los humanos frente a la multiplicidad de modos de existencia -tanto humanos y no-humanos, como vivos y no-vivos-, así como de las fricciones y divergencias puestas en juego en el CC y el Antropoceno.

El objetivo de este escrito es participar en este debate desde el contexto académico mexicano, donde éste aún es incipiente. Y contribuir en esta polémica ante la "casi total ausencia de [estudios] latinoamericanos" sobre el tema y ante la necesidad de "introducir la discusión sobre el Antropoceno en nuestros países" (García Acosta 2017: 12) ${ }^{4}$, ya que en ellos se encuentra parte de la mayor diversidad biológica, social, cultural y política del planeta (Boege 2008). Históricamente estas regiones han sido habitadas y transformadas por poblaciones indígenas (Boege 2008). Por ello, conocer las lógicas locales de estas poblaciones es imprescindible para estudiar la ecología y la política de estos territorios en disputa. En este marco, para construir mi argumento elegí el término Antropoceno, ya que, si bien es debatible, sigue siendo el más conocido en dichos contextos. Esto me permite destacar esquemáticamente las premisas y el reconocimiento de los efectos del Antropoceno con el fin de contrastarlos con la teoría etnográfica rarámuri resultado de mi trabajo de campo antropológico. Finalmente, considero que este término es problemáticamente antropocéntrico; sin embargo, me interesa examinar las reflexiones que ha suscitado el papel de los humanos, por lo que al menos para este trabajo, la noción de Antropoceno es operativa.

Para lograr este objetivo, a lo largo de este escrito daré respuesta a la siguiente pregunta: ¿Cómo vincular el conocimiento de los rarámuri que residen en la Sierra Tarahumara, México, con los procesos del CC y del Antropoceno? Mi hipótesis de trabajo es que las premisas y las implicaciones más relevantes sobre estos procesos están presentes, de forma previa y paralela, en la teoría-práctica rarámuri que definiré más adelante. Específicamente, a través del concepto de caminar-caminos y de las acciones nativas dedicadas al "cuidado del entorno" y a "sostener el mundo". Entiéndase que la analogía entre el CC, el Antropoceno y la teoría-práctica rarámuri opera por contraste. Es decir, la reflexión que presento es una traducción que destaca las diferencias antes que una comparación enfocada en las similitudes (Viveiros de Castro 2010). Por tanto, presento una traducción divergente 
entre distintos modos de existencia.

Este artículo se inserta en el proyecto posdoctoral que actualmente desarrollo titulado "'Sostener el mundo' en el Antropoceno: hacia una ecología cosmopolítica de los rarámuri de México". Esta investigación se estructura en dos momentos. Primero, en describir los conflictos ambientales por la afectación que genera, por ejemplo, la tala indiscriminada en el entorno, o por el riesgo de afectación que conllevaría su implementación (Paz 2013); así como en registrar las fricciones ambientales (Tsing 2005) en la localidad de Norogachi, Guachochi, estado de Chihuahua. Segundo, en documentar las estrategias de los rarámuri para vincularse con dichos conflictos y fricciones. Como un paso previo, es necesario realizar un ejercicio reflexivo (metodológico, teórico y político) sobre las teorías-prácticas de los rarámuri en torno al sistema socio-ecológico (de aquí en adelante SSE) en el que habitan. Como anticipa el título, vinculo el conocimiento de los rarámuri sobre los SSE con las discusiones dedicadas al CC y al Antropoceno.

Sherman Farhad (2012: 265) define el SSE como: "un sistema complejo y adaptativo en el que distintos componentes culturales, políticos, sociales, económicos, ecológicos, tecnológicos, etc. están interactuando [...]. Esto implica que el enfoque de la gestión de los ecosistemas y recursos naturales, no se centra en los componentes del sistema sino en sus relaciones, interacciones y retroalimentaciones". Esta noción redefine las interacciones de los humanos con sus entornos y, con ello, la división tajante entre los ámbitos de la naturaleza y de la cultura. Y es operativa porque en una escala más manejable para nosotros plantea un tipo de relacionalidad análoga a las que se derivan del CC y el Antropoceno. En este marco, en las siguientes páginas me pregunto ¿̇cómo entender la formulación sobre el SSE entre los rarámuri? Para responder a este cuestionamiento, es preciso considerar que la particularidad determina los elementos, las relaciones, las interacciones y las retroalimentaciones. Para el caso rarámuri planteo que la constitución de su mundo, los agentes que lo habitan, los tipos de relaciones, de sustancias y de formas de poder son particulares en términos ontológicos, epistemológicos y políticos, hecho que se expresa en el ámbito biológico, psicológico, social y cósmico (Fujigaki Lares 2015).

Así, el SSE de la Sierra Tarahumara será entendido en términos rarámuri. Para hacerlo describiré las características más importantes del SSE de la región. Posteriormente, expondré la teoría-práctica sobre el kawí (montaña, sierra, mundo, la tierra, terruño) rarámuri con el fin de contrastar este término nativo con el SSE. Después enunciaré los modos de existencia que participan de fricciones cosmopolíticas para, finalmente, describir dos formas de caminar y de caminos, definidos como la manera de comportarse en el kawí.

Basado en mi investigación etnográfica entre los rarámuri y en diálogo 
con las reflexiones conceptuales de Isabelle Stengers (2010: 37) que a su vez siguen a Félix Guattari, por modo de existencia, entiendo las condiciones necesarias para la constitución de un agente o de un agenciamiento colectivo, esto es, sus relaciones y sustancias constitutivas. En el mismo sentido, siguiendo a Stengers (2005) y a Bruno Latour (2004), concibo la cosmopolítica como la posibilidad conceptual de registrar la convergencia pragmática, en un momento concreto, entre modos de existencia ontológica, epistemológica y políticamente heterogéneos. Uno de los principios de la cosmopolítica es que dichos modos de existencia son múltiples y divergentes. De tal modo que su articulación implica la construcción de un campo común fundamentado en la convergencia y tendencialmente en el conflicto que podrían tener como escenario un sistema socio-ecológico. ¿Cómo realizar un registro etnográfico que dé cuenta de estas multiplicidades? En principio es indispensable considerar el registro y el estudio de la proliferación de fricciones, incertidumbres y "malentendidos productivos" (Tsing 2005). Así, la cosmopolítica promueve, a nivel metodológico, sumar a nuestros estudios otras composiciones del cosmos y de los agentes involucrados en la política; considerando de manera fundamental que "Cosmopolitics is, of course, a speculative concept, and its effects will first of all affect the way in which we understand ourselves and understand others in contrast to ourselves" (Stengers 2011: 256). Por tanto, es un llamado a redefinir aquello que entendemos como político (Latour 2004: 454).

Por último, la meta ulterior de este artículo es contribuir a la problematización de algunas premisas del CC y del Antropoceno a la luz de narrativas y acciones nativas y locales con el fin de potencializar nuevos caminos teóricos y prácticos. Sin duda, esto resulta indispensable para encarar la profunda mutación de nuestra relación con el mundo (Latour 2017) y para afrontar los fines del mundo que han llegado y que vendrán, así como aquellos viejos mundos que han acabado para otros (Danowski y Viveiros de Castro 2014).

\section{El sistema socio-ecológico de la Sierra Tarahumara}

La Sierra Tarahumara, ubicada en la Sierra Madre Occidental, es única en su composición ecológica, cultural y política. Esta región se caracteriza por la diversidad de sus SSE (CONABIO 2014; Tarahumara Sustentable 2019; entre otros). Por un lado, la sierra cuenta con una heterogeneidad de nichos eco-geográficos y una amplia gama de recursos naturales. Esta es la zona más importante de generación y captación de agua potable en el noroeste 
de México y el origen de tres vertientes: la vertiente del Golfo (cuenca del Conchos-Bravo), del Pacífico (cuenca del Fuerte, cuenca del Yaqui) y la vertiente del Norte (Cuenca Casas Grandes) (CONABIO 2014; González et.al. 2016: 8)..$^{5}$

Por otro lado, en esta región conviven seis grupos étnicos (pimas bajos u o'oba; los tepehuanos del norte u ódami; los guarijío o warijó, tarahumaras o rarámuri; los mestizos o blancos y los menonitas -población de origen alemán). Cada uno de ellos práctica modos particulares de vinculación con el entorno. Algunos estudios ambientales y etnográficos de la región constatan las correlaciones entre la biodiversidad y la diversidad cultural (Boege 2008; CONABIO 2014; Mancera 2015, entre otros), resaltando la importancia de la participación de los rarámuri en la producción y la reproducción del flujo genético de la biota (Bye 2011). Estos autores, también han destacado la heterogeneidad cultural, identitaria y lingüística entre los rarámuri (Bennett y Zingg 1978[1935]; Valiñas 2001; López Flores 2015).

Finalmente, en esta región, el deterioro de las relaciones dentro de los SSE es latente y en años recientes se ha intensificado (ver Guerrero 1999; Sariego 2008a, 2008b; Grupo Integral de Servicios Ecosistémicos Eyé Kawí A.C. 2014). En la Sierra Tarahumara se ejecutan violencias e injusticias estructurales de tipo social y ambiental contra los modos de existencia nativos (CONEVAL 2010; Almanza 2015; Gómez y Mayorga 2019), expresadas en: condiciones de pobreza, discriminación y deslegitimación de los conocimientos locales. Estas violencias e injusticias son producto de una historia de conflictos, fricciones y explotación que continúa hasta el presente caracterizado por al menos dos ofensivas recientes. Por un lado, con la nueva oleada de explotación de los recursos de la región (mineros, forestales, hídricos, territoriales, turísticos y humanos) que, según algunos especialistas, sólo tiene precedente en el periodo de la Conquista (López Bárcenas 2013; Comisión Interamericana de Derechos Humanos 2015; Ulloa 2017; entre otros). Y, por otro, con el impulso de los megaproyectos que, mediante discursos de desarrollistas (Rivera 2020), los gobiernos locales terminan participando en una "criminalidad ambiental del Estado" (Almanza 2016).

En México aún no se reconoce con plenitud el papel activo de "los pueblos indígenas y comunidades campesinas [en la conservación y en la generación creativa] in situ y [en el desarrollo de] recursos fitogenéticos como el germoplasma 'cultivado' por ellos" (Boege 2008: 24). Este papel no puede ser reducido a conductas innatas de los indígenas. Es necesario evitar este tipo de esencialismos y dar cuenta de las diferencias internas que constituyen las teorías-prácticas nativas, como en el caso rarámuri, así como del constatado deterioro de las prácticas y de los conocimientos nativos en 
sus relaciones con el entorno, hecho que agrava esta situación. ${ }^{6}$

En resumen, la diversidad biocultural, así como los conflictos, las fricciones y la explotación son parte del SSE actual de la Sierra Tarahumara. Queda por entender cómo estas relaciones son categorizadas y ejecutadas por los rarámuri. A continuación, describiré la noción de kawí en su contraste con la formulación del SSE que he definido brevemente. El objetivo es experimentar, mediante una traducción que tome como punto de partida la práctica y la conceptualización del kawí rarámuri, el SSE antes presentado. En este sentido, no buscaré sustituir una noción por otra. Por el contrario, expondré cómo cada una de ellas despliega aspectos, acciones y relaciones diferentes, al mismo tiempo que confluyen en la vida rarámuri. En otros términos, el SSE y el kawí serán entendidos como traducciones de versiones divergentes e incompatibles en relación.

\section{El kawí rarámuri}

A través del kawí (o sus variantes: kawi, kawé, gawí, gawé, cahuí, gawichi, kawichí, kawí huichimoba) los rarámuri categorizan y experimentan la noción de SSE. Con el fin de ofrecer un panorama amplio del kawí. A continuación expongo las definiciones registradas lingüística y etnográficamente sobre esta noción y práctica.

En los diccionarios rarámuri, Ivon Thord-Gray (1955), Simon Hilton (1993[1959]) y David Brambila (1976) reportaron que kawí es montaña, monte, mundo o la tierra, además de rancherías, campos, protuberancias en la tierra e indirectamente el lugar de nacimiento. Thord-Gray y Abel Rodríguez resaltaron que wichimoba tenía el mismo significado que kawí, esto es, "donde estamos parados" o el "mundo", considerando que "se trata del conjunto del territorio físico (valles, montes, bosque, ríos y arroyos, etcétera) en el que se desarrolla la vida social, familiar y personal, idea que otros han manejado con el término de 'territorialidad'" (Rodríguez 2015: 75). Etnográficamente, para William Merrill (1992[1988]) kawichí: "Puede referirse con crecientes grados de especificidad a 'el mundo', 'tierra', 'montañas', y 'los campos o la casa de uno'. En un sentido relativo significa 'afuera' con respecto a las áreas donde los rarámuri concentran sus actividades". También puede entenderse como "'monte' y 'suelo no limpio' en contraste con 'suelo cultivado' (wasachí) y 'área donde se vive' (bitérachi)". Siguiendo esta línea de pensamiento, " [k]awichí [...] tiene connotaciones de no humano, salvaje y, potencialmente malo, como opuesto a los valores de lo humano, domesticado y bueno en potencia y que es atribuido a las 
áreas de actividad más intensa" (Merrill 1992: 115-116). Ana Paula Pintado (2012: 268), por su parte, explica que kawé o kawí significa "Tierra", así como "la madre que los cobija con sus cerros y los protege. Se trata del lugar intermedio dentro del cosmos, donde confluyen las cosas del arriba y del abajo". Para ambos autores, el kawí es un espacio de conflicto y de fricción entre modos de existencia con diferentes valores morales y políticos.

Por su carácter innovador, me interesa problematizar con mayor detalle las propuestas etnográficas de Enrique Salmon (2000), Felice Wyndham (2009) e Isabel Martínez Ramírez (2012). Salmon señaló que los rarámuri mantienen relaciones de parentesco extendido con la naturaleza porque todos los elementos del ecosistema comparten el iwigá ("el aliento de la vida"). Este autor definió al kawí como "the place of nurturing" (Salmon 2000: 1327), donde múltiples conexiones aseguran el flujo del iwigá, regulando las relaciones entre los humanos y la naturaleza. Este proceso, denominado por Salmon como kincentric ecology o iwígara, mantiene la salud física, mental, espiritual y social y simultáneamente entrelaza la historia, la identidad, el territorio.

En sintonía con Salmon, Wydham (2009) propuso modificar las herramientas conceptuales utilizadas para explicar los vínculos ecológicos de los rarámuri. Esta autora destacó la necesidad de cuestionar la noción generalizante de recursos naturales para centrarnos en el conocimiento ecológico tradicional, particularmente en las plantas. Esta autora reflexionó sobre las "ecologías sutiles" de Félix Guattari y puso a prueba conceptos como "esferas de relación" y "líneas de interacción". Me interesa resaltar que este trabajo pondera una lógica relacional y complejiza los vínculos que establecen los rarámuri con su entorno. ${ }^{7}$

Martínez Ramírez (2012a, 2019) plantea que para los rarámuri la noción de kawí abarca un régimen de alteridad y una multiplicidad de mundos -entendidos como las distintas realidades que pese a remitir a un mismo proceso o fenómeno difieren en sus efectos-. La autora analiza dos formas de vivir disímiles que no poseen límites claros ni fijos: la forma-kawí y la forma-ejido. La forma-kawí raramuriza el espacio por medio del trabajo colectivo de los tarahumaras, en tanto que la forma-ejido es ajena a lo rarámuri pues la categoría de no rarámuri se identifica con la ausencia de trabajo en y para el colectivo. Para Martínez Ramírez, el entorno rarámuri no es un contenedor de la experiencia sino parte integral de ella, en consecuencia, la relacionalidad es fundamental para comprender el modo de vida rarámuri. En este mundo, un mismo existente puede ser varios seres. Por ejemplo, un pino puede ser un árbol con alewá (una de las nociones rarámuri para traducir "alma") y parte de una red de parentesco -tal 
como afirmaba Salmon-. Al mismo tiempo, este árbol puede ser un pino, entendido como recurso maderable. Coincidiendo con Merrill, para esta autora el kawichí también refiere a lo no domesticado y a los ámbitos dominados por el Diablo. Nuevamente observamos cómo el kawí es un concepto que implica "lo mestizo" -el tipo de alteridad más acentuada para los rarámuri. ${ }^{8}$

Pese a tener enfoques disímiles, en estas propuestas la relacionalidad es constitutiva del kawí. Este hecho resalta la importancia de las redes de socialidad que los rarámuri mantienen con una amplia gama de seres que, definidos por su alteridad, habitan el kawí. En otro lugar analicé cómo estos vínculos son indispensables y constitutivos de los modos de existencia de los rarámuri y simultáneamente son potencialmente inconmensurables, definiendo la socialidad por una constante tensión. El motivo es que dichos modos de existencia dependen de las sustancias y de las relaciones que los rarámuri obtienen de sus alteridades (Fujigaki Lares 2015, 2019). Es preciso advertir que la posición de alteridad no es exclusiva de los humanos (rarámuri y no rarámuri, vivos y muertos), ya que incluye seres-planta (Merrill 1992), piedras con poderes para enfermar y matar-conocidas como rushíwari o sukíki- (Velasco 1987), animales, los ríos, los árboles y el bosque. En este sentido, el kawí es multiespecie -sólo para utilizar una expresión en boga (Kirksey y Helmreich 2010).

En resumen, el kawí está construido por los vínculos entre las alteridades heterogéneas que lo habitan, las cuales se encuentran en constante tensión, lo que genera conflictos y fricciones inconmensurables. Estos vínculos divergen y reconfiguran las fronteras de las nociones de naturaleza y cultura que fungen como premisas del CC y el Antropoceno. Ahora describiré una expresión teórico-práctica de los rarámuri sobre los caminos y el caminar. El fin es mostrar que la relacionalidad es importante para explicar los vínculos de este pueblo con su entorno.

\section{Dos caminos-caminar rarámuri}

En los últimos años, autores rarámuri y no rarámuri de diversas disciplinas hemos reflexionado sobre los conceptos de caminante, caminar y camino. ${ }^{9}$ La palabra boé refiere en sentido estricto a "camino, vereda, sendero, carretera, pista". En sentido figurado refiere al "camino de los antepasados" (anayáguari boé), entendido como "la tradición" o "el costumbre" y también a las venas, "lá bowerá", es decir, "el camino de la sangre". Más adelante destacaré cómo los rarámuri utilizan boé y i 'simima-caminos y caminarcomo dos formas conceptuales y prácticas para describir la socialidad 
entre los diferentes seres que pueblan el kawí. La voz i 'simima (de simea) se traduce como "ir, caminar, viajar" y metafóricamente remite a "hacer, comportarse, proceder"

Para fines de mi argumento, utilizaré la fórmula rarámuri caminarcamino(s) como una síntesis que permite explicitar la acción -de caminary el tipo de comportamiento que se decide seguir -el camino-. Caminar-caminos es transversal a la teoría etnográfica rarámuri. Es decir, cruza la experiencia (individual y colectiva) porque enlaza lo fisiológico (cuerpo, almas, persona), lo psicológico (estados de ánimo, pensamientos, emociones), lo social (la socialidad, el ámbito político) y lo cósmico (vínculos con todos los seres y el mundo en general). También articula los procesos de la salud y la enfermedad, de la vigilia y el sueño, de la vida cotidiana y la ceremonial. La noción de teoría etnográfica se enmarca en un debate abierto y heterogéneo. En general, ha sido entendida como una práctica de la descripción y de reflexividad política (Goldman 1999, 2006, 2016; Nader 2011; Da Col y Graeber 2011; Martínez Ramírez 2012a; Martínez, Fujigaki y Bonfiglioli 2019, entre otros). Desde mi perspectiva, la teoría etnográfica es el resultado de la experiencia etnográfica y antropológica construida con los rarámuri con quienes conviví, así como con los análisis de otros estudiosos (rarámuri y no rarámuri). La teoría etnográfica implica comprender el modo de existencia rarámuri a través de la descripción y de la co-producción de las herramientas teóricas, metodológicas y políticas desarrolladas en y por la convivencia del trabajo de campo y el conocimiento generado entre los individuos y los distintos agenciamientos involucrados. ${ }^{10}$ Es operativo el análisis en estos términos dado que me permite registrar la convergencia pragmática entre modos de existencia múltiples y divergentes en términos ontológicos, epistemológicos y políticos.

En un trabajo reciente (Fujigaki Lares 2019) analicé cómo para los rarámuri las acciones, las narrativas, las emociones, los pensamientos y los sueños -entendidos como una unidad-son categorizados mediante dos formas de caminar-caminos. Por un lado, encontramos "el camino de los antepasados" (anayáguari boé) que ya he mencionado y, por el otro, el camino-otro (si'nú boé). La manera de comportarse y de ser implica seguir uno de estos caminos. Los dos caminos se contraponen dado que expresan posiciones morales y políticas contrarias y, al mismo tiempo, están inextricablemente enlazados. En términos rarámuri, cada uno de ellos corresponde con dispositivos de relación comandados por lo propio y por lo ajeno (identidad|alteridad) (Fujigaki Lares 2019).

En las narrativas públicas y privadas, los rarámuri reflexionan y evalúan reiterativamente su comportamiento, el de sus congéneres y el de sus 
alteridades. Discuten cómo ser y hacer como un "buen rarámuri" o como un "buen caminante" implica seguir el anayáguari boé ("camino de los antepasados", "el costumbre"), ya que de lo contrario podría seguirse el si 'nú boé o "camino-otro" ("distinto", "equivocado", "extranjero"), llegando a ser y hacer como un "mal rarámuri". En consecuencia, andar por un camino u otro repercute en los procesos e interacciones: del repokára (cuerpo) |alewá (almas), salud|enfermedad, vigilia|sueño, cotidiano|ritual, conflictos $\mid$ resoluciones, vínculos con Onorúame (El-que-es-Padre, deidad vinculada ocasionalmente con el sol), etc.

El concepto caminar-camino está anclado en el comportamiento individual y colectivo $\mathrm{y}$, por tanto, en las formas de construir un mundo habitable. En cada caminar-camino se ponen en juego valores, emociones, formas |contenidos estéticos, éticos y políticos que definen el ser y el hacer cotidiano de cada rarámuri. Como mencioné, estos caminar-caminos son transversales a toda la existencia y se expanden hacia el exterior de la sociabilidad de este pueblo.

En otro lugar definí diez personajes conceptuales, sensu Deleuze, para ejemplificar estos caminar-caminos entre humanos -rarámuri y no-rarámuri y vivos y muertos (ver Tabla 1).

Tabla 1. Personajes conceptuales que resumen los caminar-caminos de los rarámuri

\begin{tabular}{|c|c|}
\hline $\begin{array}{l}\text { Anayáguari boé o } \\
\text { "camino de los } \\
\text { antepasados" }\end{array}$ & $\begin{array}{l}\text { Si 'nú boé o } \\
\text { "camino-otro" }\end{array}$ \\
\hline $\begin{array}{l}\text { a) Rarámuri atentos a las pres- } \\
\text { cripciones éticas y políticas } \\
\text { de los mitos } \\
\text { b) Sensatos y trabajadores } \\
\text { c) Owirúame (curandero) } \\
\text { d) Gobernador(a) justo(a) } \\
\text { e) Vivos y deudos que cumplen } \\
\text { rituales mortuorios }\end{array}$ & $\begin{array}{l}\text { a) Gigantes caníbales } \\
\text { (transgresores de las pres- } \\
\text { cripciones éticas y políticas } \\
\text { de los mitos) } \\
\text { b) Transgresores sociales } \\
\text { ("locos") y perezosos } \\
\text { c) Sukurúame (hechicero) } \\
\text { d) Gobernador(a)amestizado(a) } \\
\text { e) Almas de los muertos } \\
\text { (alewá mukúame sin fiestas } \\
\text { terminadas) }\end{array}$ \\
\hline $\begin{array}{l}\text { "Buen(a) rarámuri" } \\
\text { o "buen(a) caminante" }\end{array}$ & $\begin{array}{l}\text { "Mal(a) rarámuri" } \\
\text { o "mal(a) caminante" }\end{array}$ \\
\hline
\end{tabular}

Cada uno de estos caminantes y caminos produce y circula sustancias y relaciones que, material y moralmente, son evaluados como semáti 
(hermoso, bello, bonito) o como cháti (malo, feo, perverso, extraño) (Fujigaki Lares 2015: 354-355). Así, la forma de actuar de las personas produce aspectos regenerativos y/o degenerativos en las redes de socialidad individuales y colectivas. Por ejemplo, "el camino de los antepasados" implica actuar de manera sensata, reflexionar por el bienestar común a través del trabajo y de intercambios justos, equitativos y saludables, generando bienestar colectivo. Por su parte, "el camino-otro" conlleva acciones irreflexivas, desconsideración, pereza y falta de control. Hecho que provoca enfermedades, conflictos y fricciones que resultan dañinas e, incluso, mortales. De esta manera, la forma de comportarse determina la salud o la enfermedad, las cuales son consecuencia de los vínculos sociales -abusivos y conflictivos, justos y sensatos.

Estos caminar-caminos se desarrollan en una constante tensión entre apretar (rachinawa) y distender (mokowina) -valoración estética empleada en la alfarería, los espacios rituales, la danza, las tortillas- (Fujigaki Lares 2019). Brambila (1976: 440) ejemplifica esto con los siguientes registros lingüísticos: 1) "pe rachiná kiri kemu surá" o "sé dueño de ti mismo (Lit. aprieta tu corazón)" y 2) "rachisi kíri! We tumu chi ’jáame jáwiki patzeo!" o "[i]apriétense! [i]están ustedes muy desparramados" -frase empleada por los gobernadores rarámuri (siríame) para solicitar a los presentes que se reúnan y ofrecer un nawésari (consejo)-. Así, apretar y distender remiten a las emociones y a la estética moral y corporal que, como veremos más adelante, también es política. En lo que sigue, retomo y amplio esta reflexión para examinar estos dispositivos de relación en el kawí, considerando los agentes y los agenciamientos no-humanos que constituyen una socialidad multiespecie.

Para lograrlo, parto de la premisa bajo la cual existen diferentes maneras de vinculación entre los rarámuri, el kawí y otros seres que lo habitan práctica y conceptualización nativa documentada por Salmon (kincentric ecology), Wydham y Martínez Ramírez (forma-kawí, forma-ejido)-. A manera de ejemplo, concentro mi análisis en los lazos establecidos entre los rarámuri y los pinos (o los árboles) en Norogachi, municipio de Guachochi. El fin es evidenciar que las teorías-prácticas nativas sobre dichos lazos están vinculadas con el "camino de los antepasados" y con el "camino-otro". Describo cómo la tala ha sido un vínculo entre los rarámuri y los pinos para problematizar la distinción entre: 1) el consumo familiar y 2) el consumo industrial. 


\section{Los rarámuri y los pinos}

Datos oficiales indican que todos los municipios que componen la Sierra Tarahumara se encuentran en un alto o muy alto índice de rezago social. Para ejemplificar este fenómeno, me concentro en la información del municipio de Guachochi, Chihuahua, puesto que ahí se ubica Norogachi, localidad en la que desde el 2002 realizo mi trabajo de campo. De acuerdo con el INEGI para el 2010, en Guachochi, de las casi 50 mil personas que lo habitan, 32\% no contaban con drenaje ni excusado; $52.59 \%$ no tenían electricidad y el 58\% carecía de agua entubada. Para el 2018, de los 54,366 habitantes del municipio, sólo 847 estaban inscritos en el Instituto Mexicano del Seguro Social (Secretaría De Innovación Y Desarrollo Económico, Gobierno Del Estado De Chihuahua 2018). A partir de estos datos sabemos que el 78\% de las viviendas serranas dependen de la leña y del carbón para cocinar, producir luz y calor en la temporada invernal. Por ello, talar árboles resulta indispensable para habitar esta región.

La explotación forestal -de pinos y encinos- es una industria de alta rentabilidad para el desarrollo económico de la Sierra Tarahumara. De acuerdo con la Actualización del Estudio de la Cuenca de Abasto de la Región Sur del estado de Chihuahua, Mex. (Silvicultores Unidos De Balleza, A.C. 2018), Chihuahua tiene un territorio de aproximadamente 24,705,281 hectáreas con 22,066,520 consideradas como superficie forestal. De esta superficie, un poco más de 7 millones de hectáreas está arbolada -bosques de pino, pino-encino, oyamel, encino-pino y encino-, y el 93.7\% de la madera explotada proviene del género Pinus. Entre el 2014 y el 2015, Chihuahua incrementó la producción forestal en un 16\% con un volumen de madera de 1,106,296 m3r (metro cúbico de madera en rollo), ocupando el segundo lugar nacional en producción maderable. La Cuenca de Abasto de la Región Sur del estado, región de nuestro interés, está conformada por los municipios de Guachochi, Balleza y Guadalupe y Calvo y posee una superficie arbolada de 1,976,183 hectáreas, de las cuales, el 60\% es de pino.

Guachochi cuenta con 25 plantas y centros industriales privados y ejidales. Si consideramos los productos primarios, secundarios y celulósicos derivados del pino que son autorizados legalmente, el potencial de producción y de proyección para el desarrollo de la industria forestal en la Subcuenca Guachochi asciende a 207,100,984 millones de pesos (Gómez y Mayorga 2019). Finalmente, pese a los bajos salarios y el grado de marginación de este municipio, la explotación forestal es una de las principales industrias generadoras de trabajo masculino y de ingresos familiares. 
En este contexto me interesa ubicar el hecho etnográfico de que un rarámuri puede vincularse con los pinos de diferentes maneras. Heurísticamente, examinaré dos vínculos a través de las fórmulas: pino-pariente-casa-leña y pino-madera-aserradero-dinero. ${ }^{11}$ Para la primera, los pinos son un agente con quien se comparte iwigá. El iwigá permite la vida y fluye constante e ininterrumpidamente entre los existentes (Fujigaki Lares 2009: 27; 2019: 336-339). Iwigá puede traducirse al español como "alma, espíritu, respiración, vida". Tanto lingüística como culturalmente esta palabra sintetiza la idea de que el aliento, particularmente de Onorúame, es el iwigá que da vida (Merrill1992: 223). Las iwigá están definidas por su multiplicidad, ya que una de sus capacidades es salir y entrar del cuerpo de un rarámuri. De este modo, los pinos poseen iwigá y están interconectados en el kawí, es decir, simultáneamente están vinculados con la tierra, otros árboles y plantas, con los animales, con el agua de los ríos, las lluvias y el clima en general. Así, el kawí es construido en conjunto por las relaciones de los involucrados y por el sentido de la vida de los modos de existencia que lo habitan.

Luisa Bustillos, líder e intelectual rarámuri, reflexiona claramente sobre dichos vínculos. Desde mi lectura, sus palabras traducen la teoría rarámuri en términos ecologistas y plantean cuestiones que nos dejan perplejos por su obviedad:

La naturaleza viene caminando con nosotros desde el momento en que nacemos, nosotros caminamos con la naturaleza, con el agua, con las plantas medicinales, con el sol. Todo tiene relación: el medioambiente, la naturaleza con el ser humano, con el rarámuri. [Hablar de gobernanza ambiental] es vivir respetando nuestra propia naturaleza, con todo lo que nos rodea, en nuestro espacio en donde vivimos [...] la relación tan fuerte con la naturaleza nos hace respetar. ¿̇Cómo no respetar? ¿Cómo no vivir con ellos [los pinos del bosque]? (Tarahumara Sustentable 2016) (el énfasis es mío).

Este tipo de reflexiones coexiste con la tala y el consumo doméstico de madera y leña. Sin embargo, este vínculo debe ser cuidadoso y respetuoso, ya que los árboles comparten el iwigá con los rarámuri. En palabras de los tarahumaras: se trata al pino como un pariente. ${ }^{12}$ En la práctica, los hombres son quienes, en los alrededores del pueblo de Norogachi, cortan y hacen leña con árboles secos y/o enfermos, procurando no cortar árboles pequeños, jóvenes o vivos. Tendencialmente utilizan hachas de fierro y en menor medida motosierras.

Desde la premisa rarámuri bajo la cual "todo tiene relación", todos los seres humanos deben relacionarse con cuidado y respeto pues de lo contrario el mundo rarámuri acabaría. En otras palabras, los rarámuri tienen claro 
que, literalmente, el fin del mundo podría ser una consecuencia de no seguir ciertas normas de comportamiento -planteamiento similar a las premisas del $\mathrm{CC}$ y el Antropoceno presentadas al inicio de este artículo. Esta conceptualización relacional no es nueva para los rarámuri. Las narraciones míticas aluden reiterativamente al fin de mundo, provocado por comportamientos humanos inadecuados o, simplemente, negligentes. De tal manera que la era actual es el resultado de al menos dos procesos de creación, transgresión, destrucción y reconstrucción ejecutados por Onorúame -El-que-es-Padreante el incumplimiento de los rarámuri de las prescripciones cósmicas -efectos divergentes a los del CC y del Antropoceno dada la conceptualización única y lineal del origen del mundo y de su destrucción-. Cabe señalar que dichas prescripciones no son sino las formas de etiqueta entre los agentes del mundo en turno. ${ }^{13}$ En resumen, conceptualizar a los pinos como parientes -por tanto, en conexión en el kawí y con otros existentes- tiene como correlato formas de relación concretas -cuidado y respeto-, incluso en prácticas como la tala y el consumo doméstico. Más aún, estas prácticas deberán contribuir al beneficio colectivo de los seres y de sus relaciones en el kawí. Hecho que se expresa en la práctica de la tala y del consumo moderados. Actuar por este beneficio se resume en expresiones como "cuidar juntos el entorno" y "ser los pilares que sostienen el mundo", tal como lo plantean los rarámuri.

Aún así, el trato con los pinos puede ser otro. En el marco de la explotación industrial, los rarámuri que trabajan en un aserradero tratan a estos pinos como recursos maderables que posibilitan el acceso a recursos económicos difíciles de conseguir en la región. ${ }^{14}$ Contar con un trabajo que implique permanecer en Norogachi es muy apreciado y, también, escaso. Para acceder a un salario, la mayoría de las personas debe desplazarse a las ciudades de la Sierra Tarahumara y/o del estado de Chihuahua. ${ }^{15}$ A continuación, centro mi descripción en la experiencia de los rarámuri que laboran o han laborado en el aserradero ejidal de Norogachi y, particularmente, de quienes participan en los puestos no especializados como talar los pinos. En este aserradero contratan a rarámuri y a mestizos de manera temporal, con una capacidad máxima de 30 personas. Por ello, cada 15 días el jefe de patio cambia a casi todo el personal del aserradero, principalmente a la mano de obra semi-especializada y no especializada. El salario más bajo es de 150 pesos al día, por lo que quincenalmente se ganan montos de 2 mil pesos por jornada. De este personal, aproximadamente 7 personas se dedican a la tala directa.

Los rarámuri y/o los mestizos tienen jornadas de trabajo de entre 8 y 10 horas al día. En una jornada el trabajador encargado de la tala se encontrará con el troquero -dueño y/o conductor de una camioneta- para 
ubicar los árboles que cumplen los requisitos para el corte y que fueron marcados. Las áreas de corte cada vez están más alejadas del pueblo pero dentro del ejido. Una vez identificados y cortados, el trabajador y el troquero cargan los troncos de manera ordenada para transportarlos hasta el aserradero donde serán procesados como madera. Después de cumplir el contrato los cortadores cobrarán su salario y buscarán otro trabajo en la región. Hasta el momento no he documentado gestos rituales o de otro tipo a través de los cuales los rarámuri lamenten cortar pinos para el aserradero. Sin embargo, las reflexiones explícitas sobre cómo la tala industrial e inmoderada de los pinos conduce, de facto, a consecuencias nefastas para su forma de vida son persistentes.

Desde mi punto de vista, para los rarámuri el problema no radica en cortar los pinos y en consumir sus derivados, sino en el "cómo", el "para qué" y el "cuánto". Por este motivo, una persona puede relacionarse de las dos maneras resumidas en las fórmulas: pino-pariente-casa-leña y pino-madera-aserradero-dinero. Cada una de ellas pone en marcha los dispositivos de relación de los caminar-caminos que describí y que, pese a sus contradicciones y tensiones, coexisten en los modos de existencia de los rarámuri de Norogachi.

Por un lado, la forma de relación pino-pariente-casa-leña resulta en una preocupación por custodiar colectivamente el entorno y, por ello, los rarámuri se asumen como "pilares que sostienen el mundo". La siguiente expresión, constante entre los rarámuri, corrobora este hecho: "Omarúame tibupo keta gawiwa; o-bichíwari ta tónea wiriki ena gawí (...) tamué uku 14 ata gawí tónea uchúi; a ta suwíbasa ka, chí ikimea aré ko". Es decir: "Tengamos cuidado de todo nuestro mundo; es mucha verdad que nosotros somos los pilares del mundo (...) nosotros (los tarahumares) somos los sostenes del mundo; si nos acabáramos, quién sabe qué sucedería" (Brambila 1976: 173). Otra variante de esta idea es el nombre de la Asociación Civil fundada por los rarámuri en Norogachi: "napawika tibupo kawi" que podría traducirse como "cuidemos juntos nuestro entorno" o "cuidar juntos nuestro entorno" -varios autores han documentado estos conceptos tarahumaras (Merrill 1992; Levi 1993; Montemayor 1999; Bonfiglioli 2010; Martínez Ramírez 2012, Fujigaki Lares 2015, entre otros).

Aquello que me interesa resaltar es que, al reconocer los efectos concretos de sus prácticas éticas y al plantearlas como una obligación pragmática, los rarámuri se autodefinen como responsables del cuidado ambiental. Sumado a esto, esta responsabilidad adquiere una fuerte carga generacional y temporal. En palabras del rarámuri José Baldenegro: “Defendemos lo que muchas personas antes también defendían, lo de uno, el territorio, el bosque. 
Al defenderlo ahorita, en este tiempo, es defender (para) los que vienen después de los hijos y de los nietos de uno" (Gómez y Mayorga 2019). En este sentido, el líder y defensor ambiental Julián Carrillo, rarámuri de Coloradas de la Virgen, asesinado en octubre de 2018, afirmó: "Nosotros aprendimos a defender la tierra de ver y escuchar cómo defendían los demás, viendo a los papás y a los mayores" (Gómez y Mayorga 2019).

Recapitulando, al "cuidar juntos el kawí" los rarámuri son los pilares que sostienen al mundo porque actúan de manera correcta, porque son "buenos caminantes" al transitar por el anayáguari boé ("el camino de los antepasados") y porque son "buenos rarámuri" al "estar apretados" corporal y anímicamente, al "caminar todos juntos" y al colaborar en el bienestar en conjunto. Así, los rarámuri crean constantemente el mundo que habitan a través de este dispositivo relacional.

Por otro lado, la forma de relación pino-madera-aserradero-dinero supone caminar por el camino-otro. En este marco, las acciones de las personas podrían entenderse como una búsqueda por el beneficio individual y momentáneo que resultaría ajena al beneficio colectivo en el kawí. Sin embargo, si consideramos que la tala industrial es una forma de relación relativamente reciente, es posible advertir que para los rarámuri trabajar en un aserradero para obtener dinero puede resultar extraño. Simultáneamente, trabajar en el aserradero es necesario y deseable, sobre todo en los contextos socioeconómicos mencionados. Aún así, los rarámuri de la región están conscientes que al mantener este ritmo intenso de explotación, en menos de una década, el paisaje no será reconocible por los cambios provocados en el kawí. Para ellos, estas transformaciones han sido experimentadas históricamente, por ejemplo, con la llegada de los misioneros y de los mestizos en la región, con las reformas agrarias del siglo pasado, entre otros procesos registrados (González Rodríguez 1982, 1987, 1991; Hillerkuss 1992; Deeds 1992, 2001). Ese mundo anterior ya se transformó. Sin embargo, es sabido entre las personas de este pueblo que si todos los rarámuri se vinculan con los pinos como pino-madera-aserradero-dinero el mundo colapsará nuevamente.

Como mencioné, el vínculo entablado con los pinos en los aserraderos implica el "caminar-camino-otro" o si 'nú boé. Seguir este caminar-camino tiene consecuencias que contrastan con el "caminar-camino de los antepasados" y, por tanto, con talar árboles para el consumo doméstico. Tonino Sandoval, autoridad rarámuri de Norogachi aclara esta relación en el siguiente reclamo: "esos chabochis [que] sólo quieren talar los bosques sin cuidar la naturaleza". Con el término chabochi -no rarámuri, mexicano o mestizo local de la sierra-, Sandoval hace referencia a las personas relacionadas con la tala dañina para el colectivo multiespecie del kawí. Otro ejemplo de 
este comportamiento es la narración de José Trinidad Baldenegro -rarámuri víctima de la violencia por defender el kawí:

La madera [los árboles] significa mucho para el territorio, porque es lo que mantiene la estabilidad de las aguas. El agua que cae de las nubes se filtra y ahí dura el agua. De otra manera, cuando se derriba la madera sin responsabilidad se hace un desastre, se quema el bosque. Llegan las aguas y se lleva todo, ya no hay dónde se detenga, dónde se filtre. Se va el agua" (Gómez y Mayorga 2019).

De esta forma, podemos entender este si'nú boé plantea de manera local, previa y paralela, las acciones que provocan los fenómenos globales como del CC y del Antropoceno o Capitaloceno. ${ }^{16}$ Una lección que podemos extraer de estas últimas reflexiones es la posibilidad de repensar los modelos socioeconómicos de desarrollo desde las nociones y las prácticas de caminar-caminos de los rarámuri. Pese a que estos modelos parezcan el único camino que nosotros podemos seguir, el conocimiento y las prácticas rarámuri nos plantean otras perspectivas.

Algunos rarámuri reflexionan y trabajan con ahínco en contra de estos caminar-caminos chabochi, entendidos como formas específicas del si 'nú boé (camino-otro). Particularmente combaten la tala excesiva, legal e ilegal, los megaproyectos (estatales y/o privados) mineros, acuíferos y turísticos. Ante los efectos negativos e irreversibles de estos caminar-caminos, cada vez son más numerosas las figuras de autoridad rarámuri tradicionales que se movilizan en contra de estos vínculos.

Esto no es sencillo, pues seguir el anayáguari boé (camino de los antepasados) requiere de mucho trabajo colectivo. Más aún, este esfuerzo puede resultar penoso porque mientras los rarámuri deciden comportarse como "buenos caminantes", también pueden desear las sustancias (como los salarios y todo lo que posibilita el dinero) y las relaciones (como lo que proviene de la explotación de los seres del entorno) que conforman ese camino-otro. No olvidemos que el si 'nú boé es deseable, cautiva, seduce y captura -ya sea de manera fugaz, constante o permanente--, por ejemplo, una gran cantidad de rarámuri que migra a las ciudades no regresa a la sierra (Martínez, Martínez y Mijangos 2012:78). Hecho que, vale recalcar, es un justo derecho y una decisión de autodeterminación.

La violencia es otra dificultad para andar el anayáguari boé. En los últimos años, rarámuri y no rarámuri que reivindican el cuidado de la Sierra Tarahumara han sufrido amenazas y agresiones que, en diversos casos, han concluido en el asesinato. Entre enero de 2009 y diciembre de 2018 han sido asesinados 15 defensores de territorios y bosques en la región (Gómez y Mayorga 2019). Y aún no contamos con cifras certeras para dar cuenta del desplazamiento poblacional provocado por este tipo de ataques. 
Por todo lo anterior, en la actualidad y desde una perspectiva cosmopolítica, seguir el camino de los antepasados para cuidar juntos el entorno y sostener el mundo es una forma de resistencia ante otros modos de existencia hegemónicos y avasallantes -y muchas veces violentos y peligrosos-. Por ello, es preciso evitar la folclorización que despolitiza estas posturas. Y constatar que continuar por el camino de los antepasados -es decir, querer seguir siendo y viviendo como eran y vivían "los antiguos"-, es una práctica concreta. Como conclusión puedo indicar que aún quedaría por investigar la relación entre seguir este camino de los antepasados y la movilización social.

En resumen, las dos formas de vínculo con los pinos (pino-parientecasa-leña y pino-madera-aserradero-dinero) constituyen caminar-caminos que son definidos por las formas de relación entabladas con el kawí y con los seres multiespecie que lo habitan. Seguir cada uno de estos caminar-caminos, vinculados con el camino de los antepasados (anayáguari boé) y con el camino otro (si'nú boé), tiene consecuencias contrastantes: "sostener el mundo", "cuidar juntos el entorno" y "talar los bosques sin cuidar la naturaleza". Los rarámuri pueden relacionarse de manera regenerativa con el kawí, logrando beneficios colectivos mediante el trabajo individual. O bien, pueden vincularse individualmente -logrando beneficios y regeneratividad individual-y producir degeneratividad colectiva. Como mencioné, estar apretados remite a las relaciones entre los seres del kawí estrechas y regenerativas. Esto se contrapone a "estar disperso", actuar de manera individualista y no considerar el bien común, que es la forma degenerativa de vínculos colectivos.

Los rarámuri narran constantemente cómo afrontan, al elegir uno de estos caminar-caminos, encrucijadas morales y políticas. Estas elecciones son posibilidades para crear continuamente distintos modos de existencia y mundos habitables. Ambos caminar-caminos participan de los deseos, los derechos, las decisiones y, por tanto, de la autodeterminación cosmopolítica rarámuri. La conceptualización y práctica de estos caminar-caminos implica la ejecución de actos creativos ante los discursos hegemónicos. Incluso, la capacidad de elegir entre distintas formas de relación con el entorno es una aportación para repensar los modelos de desarrollo contemporáneos que, tendencialmente, aparecen como un camino único.

Finalmente, cabe resaltar que la descripción de estos caminar-caminos es relacional. En otros términos, lo otro o lo no rarámuri no es sustancialmente definido como equivocado o erróneo y el deseo o la atracción que los rarámuri sienten por ello es una prueba. Así, cuando planteo que el camino 
otro es degenerativo se debe a los efectos negativos en contra del bienestar colectivo. En contraste, si existen formas de relación ajenas a lo rarámuri que colaboren en este bienestar, sin duda podrían ser incorporadas al camino de los antepasados y a la tradición -tal como han reportado distintas organizaciones no gubernamentales-. ${ }^{17}$ Por tanto, no es suficiente estar juntos mediante conexiones colectivas de carácter regenerativo, como proponía Salmon mediante el kincentric ecology o iwígara. La meta es conectar a todos los seres del kawí a través de complejas redes para administrar, a través de las fricciones y los conflictos, lo regenerativo (semáti) y lo degenerativo (cháti) (Fujigaki Lares 2015). Así, en cada uno de estos caminar-caminos, lo regenerativo y lo degenerativo son aspectos mutuos y relacionales, es decir, para comprenderlos es necesario dar cuenta de las relaciones que los articulan.

Marilyn Strathern (2006[1988]) menciona que la relación separa aquello que vincula. En este sentido, las relaciones con lo no rarámuri y con el camino otro constituyen el mundo rarámuri. Paralelamente, establecer los términos de esas relaciones -de esa separación- fortalece sus modos de existencia. Como mostré, estos vínculos generan fricciones y conflictos que por mucho superan nuestros conceptos de "naturaleza/cultura". Para los rarámuri, lograr el cuidado colectivo del entorno implica seguir una ética generalizada sumamente sofisticada que consiste en relacionarse de manera justa con los seres del kawí -incluso cuando son alteridades-. Como argumenté, el manejo de la tensión entre los dos caminar-caminos permite la continuidad de la existencia rarámuri en sus propios términos y su autodeterminación existencial.

\section{Conclusiones}

Las discusiones sobre el CC y el Antropoceno plantean cuestiones ineludibles. Por ejemplo, la inevitable consciencia de la toxicidad antropogénica (Povinelli 2016) que ha modificado irreversiblemente el planeta a escalas y magnitudes nunca vistas, resultando peligroso para la vida de las diferentes especies que lo habitan. Por esta toxicidad antropogénica (con impactos climáticos, geológicos, sociales y políticos) es ineludible reflexionar sobre los dispositivos de relación de nuestros modos de existencia. Un punto de debate actual es la relacionalidad entre la humanidad y el planeta. Por una parte, esto nos obliga a replantear las divisiones entre la naturaleza y la cultura expresadas en díadas como humanos/no-humanos, mente/cuerpo, vivos/ muertos/no-vivos, yo/otros, entre otros. Por otra, nos permite problematizar las consecuencias ambientales, humanas y políticas de estas divisiones. 
A partir de estas discusiones, distintas disciplinas del conocimiento natural y social han desarrollado herramientas técnicas y conceptuales que revelan la existencia de agentes y de agenciamientos diversos que habitan el mundo.

De este modo, los debates del CC y del Antropoceno son la forma contemporánea mediante la cual nos percatamos de esta inusual emergencia de agentes, así como de nuestros dispositivos de relación que afectan al mundo a la vez que lo construyen. Este modo de existencia -responsable de acelerar el CC- coexiste con otros más resilientes, articulados a través de fricciones y conflictos. Un punto de acuerdo en dichos debates es la búsqueda para identificar estrategias locales que representen alternativas ante las teoría-prácticas hegemónicas que, directa o indirectamente, han propiciado el CC y el Antropoceno.

El objetivo de este artículo fue problematizar cómo la teoría etnográfica y las acciones concretas de los rarámuri sobre los caminar-caminos son análogas, previas y paralelas a las premisas y al reconocimiento de los efectos del CC y del Antropoceno. Por ejemplo, dicha teoría etnográfica reconoce una multiplicidad de agentes y de agenciamientos internos y externos al kawí, así como de distintos vínculos divergentes y de fricciones inconmensurables, y en este sentido es que puedo hablar de estrategias cosmopolíticas. Todo ello expresa que los rarámuri han reflexionado desde hace tiempo sobre el impacto de las acciones humanas en el entorno, ya sea cuidándolo o colaborando en el latente riesgo de que el mundo acabe, tal como está inscrito en sus mitos de origen. En términos rarámuri, los vínculos, sean individuales o colectivos, y las acciones concretas determinarán el mundo que se habitará, ya que seguir un camino específico-camino de los antepasados (anayáguari boé) y el camino otro (si' nú boé)-implica participar de flujos particulares de relaciones y de sustancias regenerativas|degenerativas. Como hemos visto en el caso de los asesinatos de los líderes y defensores ambientales, algunas batallas por el cuidado del entorno son asimétricas. Particularmente cuando se mantienen con aquellos seres que tienen un vínculo con el entorno basado en la lógica extractivista. A lo largo de este artículo argumenté que seguir cualquiera de estos caminos tiene consecuencias regenerativas|degenerativas. De tal manera que no existe una única resolución a los conflictos y a las fricciones cosmopolíticas desarrolladas entre los distintos modos de existencia que coexisten en el kawí.

En este sentido, la convergencia de esos caminos no es equivalente a una fusión de horizontes $\mathrm{y}$, justamente, ese mecanismo fundamenta la teoría etnográfica rarámuri que he propuesto entender. De esta manera, los cuestionamientos individuales y colectivos de los rarámuri sobre este ámbito expresan una búsqueda para crear estrategias locales con una visión global 
incluyente. En otras palabras, los rarámuri reflexionan y actúan desde sus propios términos en torno a procesos más amplios (económicos, políticos, climáticos, etc.). Así, la teoría etnográfica rarámuri no sólo se circunscribe a un discurso político sobre el cuidado del entorno. Ésta es, ante todo, un proyecto de existencia.

Examinar el kawí mediante una traducción divergente o a través del contraste con el SSE generó heurísticamente una visión integral y sistémica que posibilitó sumar al análisis otra imagen de las correlaciones entre la naturaleza y la cultura. Por ejemplo, el kawí es per se multiespecie. Por tanto, está definido por los conflictos y las fricciones en las cuales los humanos son un modo de existencia entre otros que tiene la responsabilidad ética y política de decidir cómo entablar vínculos específicos. En consecuencia, a través del kawí es factible conocer una teoría-práctica sobre los lazos de los rarámuri con las alteridades multiespecie que lo integran y lo habitan.

De manera análoga, los debates sobre el CC y el Antropoceno nos exhortan a decidir cotidianamente cómo comportarnos y cómo relacionarnos con nuestras propias alteridades -sean humanas o no, vivas, muertas, no vivas, etcétera-, ya que esto afecta la existencia global. Por un camino diferente, estos debates ofrecen posibilidades para imaginar prácticas emergentes que podemos sumar a nuestras estrategias cosmopolíticas. Los rarámuri reconocen la irrupción histórica de diversas alteridades que han modificado radicalmente su mundo a través de fuerzas degerativas|regenerativas. Más aún, lo degenerativo ha sido un hecho reconocido como dado desde hace mucho tiempo (Fujigaki Lares 2015 y 2019). Ante esto, cabe preguntarse lo siguiente, si ellos han permitido que sus alteridades los afecten ipor qué nosotros no podríamos hacerlo?

Por todo ello, la teoría etnográfica rarámuri es -tal como afirmó Bruce Albert (1995: 23) sobre las estrategias de existencia yanomani- "más que una ecología política y más que una estrategia de conservación de la biodiversidad". ${ }^{18}$ Esta teoría etnográfica es una muestra de que aquello que entendemos en ciertos contextos académicos como cambio climático, cosmopolítica y Antropoceno podría traducirse al régimen de la alteridad constitutiva amerindia (Lévi-Strauss 2004[1973], 1992[1991]; Viveiros de Castro 2010; Fujigaki Lares 2019). Por ejemplo, en clave rarámuri, dicha alteridad se manifiesta como la tensión entre el caminar-camino anayáguari boé y el caminar-camino si 'nú en el kawí. Seguir una u otra manera de caminar-camino es una decisión personal y política, individual y colectiva, humana y con todo en relación (tal como mencionó Luisa Bustillos). Así, los rarámuri sostienen -y por ello crean- constantemente el mundo que habitan o colaboran en su colapso. 
Recebido em: 25 de novembro de 2019

Aprovado em: 28 de fevereiro de 2020

Alejandro Fujigaki Lares

Antropólogo Social por la Universidad Autónoma del Estado de Morelos.

Maestro y doctor en Antropología por la UNAM. Realizó una estancia posdoctoral en el Museo Nacional, de la Universidad Federal de Rio de Janeiro, Brasil, y actualmente realiza un una estancia posdoctoral en el Instituto de Investigaciones Sociales en la UNAM. Ha realizado diversas temporadas de trabajo de campo desde el 2002 entre los rarámuri de Chihuahua, México.

https://orcid.org/0000-0002-1432-3287

E-mail: alejandrofujigaki@gmail.com 


\section{Notas}

1 UNAM, Becario del Programa de Becas Posdoctorales en la UNAM, Instituto de Investigaciones Sociales, asesorado por la Dra. Elena Lazos Chavero. Este trabajo fue apoyado por UNAM-PAPIIT IN-404220. Laboratorios de historia indígena contemporánea, coordinado por la Dra. Isabel Martínez Ramírez.

2 Agradezco especialmente a Isabel Martínez Ramírez por la atenta lectura, las correcciones puntales y las opiniones que nutrieron las versiones previas de este trabajo. También agradezco a Elena Lazos y a Emmanuelle Helio por las sugerencias y comentarios que me aportaron. Mi gratitud a quienes dictaminaron el manuscrito ya que sus agudas y generosas observaciones permitieron ser más preciso en mis planteamientos y, así, enriquecer mi texto. Versiones previas de este estudio las presenté en el Seminario de estudios mesoamericanos. Temas, horizontes y desafíos (en la Universidad de Chile, Chile); en el Simposio Conflictos Ecológicos en América Latina: Estado, Extractivismo y Comunidad desde visiones divergentes (IIA-UNAM, México) y en el Seminario Anual de la Red de Estudios sobre Sociedad y Medio Ambiente (RESMA) (IIS-ColSan, México). Agradezco a los organizadores y participantes por las reflexiones generadas en estos foros.

3 Sólo por citar algunos trabajos representativos: Latour 2004; Stengers 2005; 2014, 2015; Informe Mundial Sobre Ciencias Sociales. Cambios Ambientales Globales 2013; Haraway 2015; Chakrabarty 2016; Ulloa 2017; Adeney 2017; Mauelshagen 2017; Trischler 2017. Ver también la página http://www.anthropocene-curriculum.org.

4 Además de la compilación de García Acosta, algunos trabajos latinoamericanos recientes son Palacio, Vargas y Hennessy (2018), Svampa (2019) y Tola et. al. (2019), entre otros.

5 Baste con mencionar una característica: estos nichos oscilan entre altas montañas de bosque templado de hasta $3200 \mathrm{msm}$ con temperaturas de hasta $-15^{\circ} \mathrm{C}$ y profundas barrancas de selva tropical de hasta $200 \mathrm{msn}$ con $48^{\circ} \mathrm{C}$, que se encuentran en una extensión de casi $65,000 \mathrm{~km}^{2}$ distribuida en 23 municipios del estado de Chihuahua. Además, su importancia ecológica reside en "generar agua, oxígeno, biomasa y biodiversidad" y en ser una fuente de beneficios primordiales para los habitantes del suroeste del Estado de Chihuahua así como para los del noroeste mexicano (Sariego 2002; CONABIO 2014; González et. al. 2016).

6 Al comparar los registros que Edward Palmer realizó en la región hace más de cien años con las prácticas rarámuri actuales, el etnobotánico Robert Bye menciona que "en poco más de un siglo se perdió el 37\% del conocimiento herbolario originado en la Sierra Tarahumara" (Guzmán 2007).

7 Para Salmon y Wydham, la relación de los rarámuri con su entorno tiende al equilibrio. No concuerdo del todo con esta idea. Si bien los rarámuri tienen una relación más equilibrada en contraste con los mestizos, aquella coexiste con conflictos y fricciones de carácter multiespecie que son parte integral de la sociabilidad. Por 
ello, es importante mantener buenas relaciones con todos los seres que lo habitan, ya que el equilibrio es continuamente construido y difícil de alcanzar. En otro lugar, propuse que la noción de iwigá constituye una posibilidad para comprender el flujo divergente e incompatible de sustancias y relaciones regenerativas y degenerativas entre los diferentes agentes multiespecie del colectivo rarámuri (Fujigaki Lares 2009, 2015, 2019).

8 En términos muy generales, lo mestizo para los rarámuri refiere a los blancos serranos.

9 Los trabajos de Isabel Martínez Ramírez (2008 y 2012) constituyen el análisis más detenido sobre este tema. Sin embargo, Montemayor (1999) destacó previamente la importancia de estas nociones. Posteriormente esta relevancia fue anotada por Aguilera (2005, 2014), Fujigaki Lares (2005, 2009, 2014, 2015), Fujigaki y Martínez (2008 y 2012), Bonfiglioli (2008 y 2014), Martínez R. (2014 y 2014b), Martínez y Fujigaki (2011 y 2012), Pintado (2012) y Rodríguez López (2015). El trabajo de "Kite amachíala kiya nirúami. Nuestros Saberes Antiguos" de Juan Gardea y Martín Chávez (1998) plantea una aportación de los propios rarámuri al conocimiento sobre estas nociones. Es evidente que el origen creativo de estas teorías-prácticas son de los rarámuri, no de quienes reflexionamos al respecto pese a que de alguna manera también influimos en su desarrollo escrito.

10 Esto conlleva que no existe Una teoría etnográfica para ningún colectivo; ya que será el resultado relacional específico desde el cual se crea. Advierto que cuando refiero a "lo rarámuri" no aludo a la teoría-práctica de todas las personas que se autoadscriben como rarámuri. Por el contrario, remite al resultado de mi específica experiencia relacional. Por ello, lo que presento en este artículo es una "variación equívoca" (Viveiros de Castro 2010; Fujigaki Lares 2015; Martínez, Fujigaki y Bonfiglioli 2019) de la teoría etnográfica o teoría-práctica rarámuri.

11 Con base en una perspectiva diacrónica, Martínez Ramírez (2019) examinó esta ecuación. Para la autora, cada una de estas fórmulas remite a un modo de historicidad particular. Por ello, analiza las narrativas de los procesos bajo los cuales los pinos y los bosques llegaron a ser productos forestales y también parientes, así como sus efectos convergentes y disyuntivos.

12 No está demás mencionar que este parentesco difiere de nuestras propias nociones sobre el tema. Siguiendo a Isabel Martínez (2019: 138), tratar a un existente como un pariente implica seguir "normas de cortesía y de cuidado concretas". Por tal motivo, tratar a los pinos al tratar como madera afecta los lazos parentales relacionalmente, por ejemplo, con Onorúame y con sus nietos. Agradezco el señalamiento del o de la dictaminadora de este artículo por advertir el paralelo de esta teoría etnográfica con la propuesta de Donna Haraway (2016), Staying with the Trouble: Making Kin in the Chthulucene. Particularmente, respecto a los cuidados generalizados entre los diferentes seres del mundo. De ahí que también resulta muy interesante el concepto de Salmon kincentric ecology o iwígara.

13 Para los rarámuri, como para otras poblaciones amerindias (Danowski y 
Viveiros de Castro 2014), el "fin del mundo" es más una experiencia histórica latente que una idea de porvenir con tintes meramente esotéricos. Su mundo y sus modos de existencia, como tales, colapsaron y acabaron ante el proceso de conquista, colonización y la creación del Estado-nación mexicano. El proceso de creación del mundo, transgresiones sociales, destrucción del mundo y una nueva creación es un dispositivo de relación. En este sentido, el Antropoceno (y cualquiera de sus variantes occidentales) ya estaría de alguna manera previsto en el pensamiento rarámuri. Este dispositivo mítico de creación, transgresión, destrucción, nueva creación es fundamental para comprender el modo de existencia rarámuri.

14 En la Sierra Tarahumara hay aserraderos privados y ejidales. Estos varían en su tamaño, así como en los índices de producción y en el procesamiento de la madera. La mano de obra requerida es especializada, semi-especializada y no especializada, acorde con la maquinaria (Salazar 2009).

15 Los rarámuri cuentan con grados de escolaridad que van del analfabetismo hasta los profesionales con carrera técnica, licenciatura y posgrados. La mayoría de los rarámuri de la región miran con buenos ojos laborar en el aserradero.

16 Aquí sería más específico utilizar Capitaloceno porque enfatiza las relaciones de producción que son estructurales a la tala. El Capitaloceno es entendido como una "crítica al Antropoceno, al centrarse en la acción humana cruzada por relaciones desiguales de poder político y económico, características del capitalismo global como causante del cambio climático, y proponer análisis que destacan la valoración y apropiación de naturalezas y territorios como ejes de las transformaciones ambientales" (Ulloa 2017: 60).

17 Los vínculos entre tradición, mitología y política rarámuri los desarrollaré en otros trabajos.

18 Las analogías etnográficas, políticas y teóricas entre rarámuri y yanomami, inspiradas en el trabajo de Kopenawa y Albert (2010) serán trabajadas en trabajos posteriores. 


\section{Bibliografía}

ADENEY THOMAS, Julia. 2017. "Historia económica en el Antropoceno: cuatro modelos". Desacatos, 54:28-39.

AGUILERA, Sabina. 2005. La faja ralámuli, Tesis de Licenciatura en Etnología, México: ENAH.

2014. "La trama de las fajas", en Isabel Martínez (Coord.) Artes de México: Tarahumaras. El camino, el hilo, la palabra, No. 112, México: pp.54-59.

ALBERT, Bruce. 1995. "O ouro canibal e a queda do céu: uma crítica xamânica da economia política da natureza". Série Antropologia, 174. Brasília: Universidade de Brasília.

ALMANZA ALCALDE, Horacio. 2015. "La concepción de la territorialidad indígena: la comunidad rarámuri de Choréachi". Espacialidades. Revista de temas contemporáneos sobre lugares, política y cultura, 5(2): 77-115. . 2016. "Criminalidad ambiental de Estado en los territorios indígenas del norte de México", en Di Giminiani, Piergiorgio, Ángel Aedo y Juan Loera, Ecopolíticas globales. Medio ambiente, bienestar y poder, Hueders, Chile.

ANTHROPOCENE WORKING GROUP. 2019. "What is the Anthropocene? Current Definition and Status". Subcomission on Quaternary Stratigraphy. Disponible en: http://quaternary. stratigraphy.org/working-groups/anthropocene/ [consultado 26/10/2019].

BENNETT, Wendell y ZINGG, Robert. 1978. Los tarahumaras. Una tribu india al norte de México. México: INI. BOEGE SCHMIDT, Eckart. 2008. El patrimonio biocultural de los pueblos indígenas de México. Hacia la conservación in situ de la biodiversidad y agrodiversidad en los territorios indígenas. México: INA-CDI.
BONFIGLIOLI, Carlo. 2008. "El yumári, clave de acceso a la cosmología rarámuri", Cuicuilco 15(42), México:45-60.

. 2014. "La si'píraka, camino e instrumento del poder chamánico", en Isabel Martínez (Coord.) Artes de México: Tarahumaras. El camino, el hilo, la palabra, No. 112, México. México:22-28.

BRAMBILA, David. 1976. Diccionario Rarámuri-Castellano (Tarahumar). México: Obra Nacional de la Buena Prensa.

BYE, Robert, Edelmira Linares, Teodolinda Balcázar, Delia Castro, Myrna Mendoza. 2011. "Reciprocidad etnobotánica en la Sierra Tarahumara: experiencias en educación ambiental". Seminario La Etnobiología y su Contribución sobre las Estrategias de Conservación de los Recursos Naturales. México: INEc-SEMARNAT.

CENTRO MARIO MOLINA. 2017. "¿Qué es el cambio climático?". Centro Mario Molina, México. Disponible en: http://centromariomolina.org/ cambio-climatico/temas/educacion-en-cambio-climatico/ [consultado 26/10/2019]

CHAKRABARTY, Dipesh. 2016. "Clima e historia: cuatro tesis". Pasajes: Revista de pensamiento contemporáneo, 31: 51-69.

CIDH. 2015. "Pueblos indígenas, comunidades afrodescendientes y recursos naturales: Protección de derechos humanos en el contexto de actividades de extracción, explotación y desarrollo". Comisión Interamericana de Derechos Humanos. Disponible en: http://www.oas.org/es/cidh/informes/ pdfs/industriasextractivas2016.pdf [consultado 26/10/2019] 
CONABIO. 2014. La biodiversidad en Chihuahua: Estudio de Estado. México: CONABIO.

CRUTZEN, Paul y STOERMER, Eugene. 2000. "The 'Anthropocene'". Global Change Newsletter, 41:17-18.

CRUTZEN, Paul. 2002. "Geology of Mankind". Nature, 415(6867):23.

DA COL, Giovani y GRAEBER, David "The return of ethnographic theory", HAU: Journal of Ethnographic Theory 1 (1):vi-xxxv.

DANOWSKI, Déborah y VIVEIROS DE CASTRO, Eduardo. 2014. Há mundo por vir? Ensaio sobre os medios e os fins. Florianópolis: Cultura e Barbárie e Instituto Socioambiental.

DEEDS, Susan. 1992. "Las rebeliones de los Tepehuanes y Tarahumaras durante el siglo XVII en la Nueva Vizcaya". In: Y. Campbell (ed.), El contacto entre españoles e indígenas en el Norte de la Nueva España. Ciudad Juárez: Universidad Autónoma de Ciudad Juárez. pp. 9-40.

. 2001. "Resistencia indígena y vida cotidiana en la Nueva Vizcaya. Trastornos y cambios étnico-culturales en le época colonial". In: C. Molinari y E. Porras (coords.), Identidad y cultura en la Sierra Tarahumara. México: INAH-H. Congreso del Gobierno del Estado de Chihuahua. pp. 55-69.

FARHAD, Sherman. 2012. "Los sistemas socio-ecológicos: Una aproximación conceptual y metodológica". In: XIII Jornadas de Economía Crítica. Sevilla: Jornadas de Economía Crítica. pp. 265-280.

FUJIGAKI LARES, Alejandro. 2005. Muerte y persona. Ensayo sobre rituales mortuorios en una comunidad de la Sierra Tarahumara, Tesis de licenciatura en Antropología Social, Universidad Autónoma del Estado de Morelos.
2009. La muerte y sus metáforas. Ensayo sobre la ritualidad mortuoria y sacrificial rarámuri en el noroeste de México. Tesis de Maestría, IIA-UNAM. . 2014. "Construir el camino del olvido. Rituales mortuorios". In: I. Martínez (coord.), Artes de México: Tarahumaras. El camino, el hilo, la palabra, 112. México: Artes de México. pp. 30-37.

. 2015. La disolución de la muerte y el sacrificio. Contrastes de las máquinas de transformaciones y mediaciones de los rarámuri y los mexica. Tesis de doctorado, IIA-UNAM.

. 2019. "Caminos que bifurcan y multiplican mundos. Alteridades|Identidades entre los rarámuri de Chihuahua". In: I. Martínez, Al. Fujigaki \& C. Bonfiglioli (coords.), Reflexividad y alteridad I. Estudios de caso de México y Brasil. México: IIH-IIA-UNAM.

FUJIGAKI, Alejandro e Isabel MARTÍNEZ. 2008. "Vida y muerte: La composición del ser humano entre los rarámuri de la Alta Tarahumara", El norte de México: Entre Fronteras, México: ENAHNM-INAH.

. 2012. "'Locura' y transgresión social: la noción de lowíame entre los rarámuri de México", en González Sobrino, Blanca Zoila, (Coord.) Entre tarahumaras, coras y huicholes. Algunos aspectos sobre la "locura", México: IIA-UNAM.

GARCÍA ACOSTA, Virginia (coord.). 2017. Desacatos. Cambio Climático y Antropoceno, 54.

GARDEA García, Juan y CHÁVEZ Ramírez, Martín. 1998. Kite amachíala kiya nirúami. Nuestros Saberes Antiguos, México: Gobierno del Estado de Chihuahua, Dirección General de Educación y Cultura, Oficinal Regional para América Latina y El Caribe de la UNESCO y Coordina- 
ción de Investigación y Desarrollo Académico Chihuahua.

GOLDMAN, Marcio. 1999. "A Experiência de Lienhardt: Uma Teoria Etnográfica da Religião". Religião e Sociedade 19 (2): 9-30.

. 2006. "Alteridade e Experiência: Antropologia e Teoria Etnográfica". Etnográfica X (1): 161-173.

2016. "Cosmopolíticas, Etno-Ontologías y Otras Epistemologías". Cuadernos de Antropología Social 44: 27-35.

GÓMEZ DURÁN, Thelma y MAYORGA, Patricia. "Sin territorio no somos nada: defensores de la Sierra Tarahumara luchan contra el despojo". Tierra de Resistentes, México. Disponible en: https://contralacorrupcion.mx/ tierra-resistentes/mexico/ [consultado 26/10/2019]

GONZÁLEZ DÍAZ, Isela, Ernesto PALENCIA, Víctor MARTÍNEZ, Elvira VILLARREAL, Horacio LAGUNAS, Juan RÍOS, Diana VILLALOBOS y María Teresa GUERRERO 2016. Informe: Derechos territoriales de los pueblos indígenas de la Sierra Tarahumara. El caso de las comunidades de Bacajípare, Bosques de San Elías Repechique, Choréachi (Pino Gordo), Coloradas de la Virgen, El Mochomo, Huitosachi, Mala Noche y Mogótavo. México: Alianza Sierra Madre A.C.-Tierra Nativa A.C.-Consultoría Técnica Comunitaria A.C.

GONZÁLEZ RODRÍGUEZ, Luis. 1982.

Tarahumara. La sierra y el hombre. México: FCE. . 1987. Crónicas de la Sierra Tarahumara. México: SEP.

. 1991. "Testimonios sobre la destrucción de las misiones tarahumaras y pimas en 1690". Estudios de Historia Novohispana, 10:189-235.

GRUPO INTEGRAL DE SERVICIOS ECOSISTÉMICOS EYÉ KAWÍ A.C.
2014. Diagnóstico sobre determinantes de deforestación y degradación forestal en zonas prioritarias en el estado de Chihuahua. México: Alianza México para la Reducción de Emisiones por Deforestación y Degradación. GUERRERO, María Teresa. 1999. La industria forestal y los recursos naturales en la Sierra Madre de Chihuahua: impactos sociales, económicos y ecológicos. México-Estados Unidos de América: Comisión de Solidaridad y Defensa de los Derechos Humanos-Texas Center for Policy Studies.

GUZMÁN, Fernando. 2007. "Al rescate de plantas medicinales", El Universal, México. [29 de noviembre de 2007].

HARAWAY, Donna. 2015. "Anthropocene, Capitalocene, Plantationocene, Chthulucene: Making Kin". Environmental Humanities, vol. 6: 159-165.

HARAWAY, Donna, Noboru ISHIKAWA Scott F. GILBERT, Kenneth OLWIG, Anna L. TSING, Nils BUBANDT. 2015. "Anthropologists Are Talking - About the Anthropocene", Ethnos 81(3):1-30, November 2015

HILLERKUSS, Thomas. 1992. "Ecología, economía y orden social de los tarahumaras en la época prehispánica y colonial". Estudios de Historia Novohipana, 12:9-62.

HILTON, Simon. 1993 [1959]. Diccionario Tarahumara de Samachique de Chihuahua, México, Arizona, E.U.A. Instituto Lingüístico de Verano.

IPCC. 2013. Cambio climático 2013. Bases físicas. Resumen para responsables de políticas. Suiza: Grupo Intergubernamental de Expertos sobre el Cambio Climático.

KIRKSEY, S., y HELMREICH, S. 2010. "The emergence of multispecies ethnography". Cultural anthropology, 25(4): 545-5761): 1-30.

KOPENAWA, Davi y ALBERT, Bruce. 2010. A queda do céu. Palavras de un 
xamã yanomami. Sao Paulo: Companhia das Letras.

LARTIGUE, François. 1983. Indios y bosques. Políticas forestales y comunales en la Sierra Tarahumara. México: Centro de Investigaciones y Estudios Superiores en Antropología Social.

LATOUR, Bruno. 2004. "Whose Cosmos? Which Cosmopolitics? A Commentary on Ulrich Beck's Peace Proposal". In: Common Knowledge, 10(3):450-462.

. 2017. Cara a cara con el planeta. Una nueva mirada sobre el cambio climático alejada de las posiciones apocalípticas. Buenos Aires: Siglo XXI Editores.

LÉVI-STRAUSS, Claude. 1991. Historia de Lince. Barcelona: Anagrama.

. 2004. "Jean-Jacques Rousseau, fundador de las ciencias del hombre". In: Antropología estructural. Mito, sociedad, humanidades o Antropología estructural II. México: Siglo XXI Editores. pp. 37-45.

LÉVI, Jérome. 1993. Pillars of the Sky. The Genealogy of Ethnic Identity among the Rarámuri-Simaroni (Tarahuamras-Gentiles) of Northwest Mexico. Tesis Doctor of Philosophy, Harvard University, Cambridge, Massachusetts.

LÓPEZ BÁRCENAS, Francisco. 2013. "¿Qué hacemos con los indios? Pueblos indígenas y desarrollo: entre las políticas gubernamentales y el 'buen vivir'". Papeles de Población, 19(77):177-192.

LÓPEZ FLORES, Oscar Adrián. 2015.

"Echi simaroni cho rarámuri juko" (Ese cimarrón también es rarámuri). Descripción del concepto de alteridad simaroni entre los rarámuri pagótame del ejido de Aboreáchi. Tesis de licenciatura, ENAH.

MANCERA-VALENCIA, Federico. 2015. Patrimonio biocultural de Chihuahua.
México: Instituto Chihuahuense de Cultura- CONACULTA.

MARTÍNEZ RAMÍREZ, Isabel. 2012a. Alteridad, multiplicidad y reversibilidad en clave rarámuri. Crónica de un viaje por la antropología del otro. Tesis de doctorado, Instituto de Investigaciones Antropológicas, UNAM.

. 2012b. "Tejiendo como caminos la vida social: teoría rarámuri de la sociedad y la persona", en Arturo Gutiérrez (Editor.) Hilando el noroeste. Nudos, redes, vestidos, textiles, COLSAN-COLEF. México: 555-562. . 2014. "Crear un mundo caminando", en Isabel Martínez (Coord.) Artes de México: Tarahumaras. El camino, el hilo, la palabra, No. 112, México: 54-59.

2019. "El otro del otro. Entre dos narrativas sobre la explotación forestal de la Sierra Tarahumara, Chihuahua, México", Revista de El Colegio de San Luis. Nueva época. Año IX, número 19, mayo a agosto de 2019, El Colegio de San Luis, México.

MARTÍNEZ, Isabel, Alejandro FUJIGAKI, Carlo BONFIGLIOLI (Coords.). 2019., Reflexividad y alteridad I. Estudios de caso en México y Brasil, México: IIH-IIA-UNAM.

MARTÍNEZ R., Isabel y Alejandro FUJIGAKI. 2011. "Los caminos de la muerte: un modelo de estudio regional para el noroeste de México", en Bonfiglioli, Carlo, Arturo Gutiérrez, Marie-Areti Hers y Danna Levin, Las vías del noroeste III. Genealogías y transversalidades, México : IIA-IIE-UNAM.

. 2012. "Entre la fisicoquímica y el alma: Relaciones entre seres-planta y nociones de locura en el Noroeste de México", en González Sobrino, Blanca Zoila, (Coord.) Entre tarahumaras, coras y huicholes. Algunos aspectos sobre la "locura", México: IIA-UNAM. 
MARTÍNEZ R., Isabel; MARTÍNEZ, Jorge y MIJANGOS, Nashielly. 2012. "Para seguir siendo lo que se debe ser: parentesco, grupos domésticos y migración entre los rarámuri". In: M. E. Olavarría y I. Martínez (coords.), Estudios sobre parentesco rarámuri y ranchero en el noroeste de México. México:UAM-Iztapalapa.

MAUELSHAGEN, Franz. 2017. "Comentario: Reflexiones acerca del Antropoceno". Desacatos, 54:74-89.

MERRILL, William. 1992 [1988]. Almas rarámuris, Colecc. Presencias No. 48, México: INI-CONACULTA.

MONTEMAYOR, Carlos. 1999. Los tarahumaras. Pueblo de estrellas y barrancas. México: Editorial Aldus.

MOORE, J. W. (ed.) (2016). Anthropocene or Capitalocene? Nature, History and the Crisis of Capitalism. Kairos, Oakland.

NADER, Laura. 2011. "Ethnography as theory", HAU: Journal of Ethnographic Theory 1 (1): 211-219.

ONU. 2019. "Cambio climático". Naciones Unidas. Disponible en: https://www.un.org/es/sections/issues-depth/climate-change/index.html [consultado 26/10/2019]

PALACIO Germán, VARGAS, Alberto y HENNESSY, Elizabeth. 2018. "Antropoceno o Capitaloceno en fricción. Des-encuentros entre Geociencias e Historia", en: Alimonda, H., Toro Pérez, C. y Martín, F. (coords.). Ecología política latinoamericana. Pensamiento crítico y horizontes emancipatorios en clave sur, volumen II, pp. 265-288, CLACSO, Buenos Aires.

PAZ, María Fernanda. 2014. "Conflictos socioambientales en México: ¿qué está en disputa?". In: M. F. Paz y N. Risdell (coords.), Conflictos, conflictividades y movilizaciones socioambientales en México. Problemas comunes, lecturas diversas. México: UNAM-CRIM-Porrúa. pp. 13-58.

POVINELLI, Elizabeth. 2016a. Geontologies: requiem for late liberalism. Durham: Duke University Press. . 2016b. "Depois de outras naturezas e novas culturas, um outro modo". In: Catálogo $32^{a}$ Bienal de São Paulo. Incertezas Vivas. São Paulo: Fundação Bienal de São Paulo: 76-85.

PINTADO, Ana Paula. 2012. Los hijos de Riosi y Riablo. Fiestas grandes y resistencia cultural en una comunidad tarahumara de la barranca, INAH, México, 2012.

RIVERA Acosta, Juan M. 2020. "'Nada más vienen y nos avientan cosas'. Desarrollo y conflicto ecológico en la Sierra Tarahumara". (Manuscrito). RODRÍGUEZ, Abel. 2015. "Conceptos próximos e interpretación distante: Espacio y tiempo en el pensamiento rarámuri". Anales de Antropología, 49(2):73-100.

. 2017. "Comunidad y organización social rarámuri en el alto río Conchos". Chihuahua Hoy, 15(15):147-178.

SALAZAR GONZÁLEZ, Denisse Ariadna. 2009. Entre el mundo rural y el trabajo industrial. México: Instituto Chihuahuense de la Cultura.

SALMON, Enrique. 2000. "Kincentric ecology: Indigenous perceptions of the human-nature relationship". ECOlogical Applirarion,10(5):1327-1332.

SARIEGO RODRÍGUEZ, Juan Luis, ARELLANO RODRÍGUEZ, Angélica Rocío; FUJIGAKI LARES, José Alejandro; GAONA PANDO, Georgina; NAVA CANO, José Omar; PÉREZ JUÁREZ, Omar Hazzael y SALAZAR GONZÁLEZ, Denisse Ariadna. 2008. Evaluación cualitativa de impacto del programa oportunidades de largo plazo, en zonas rurales, Manuscrito. 
SARIEGO RODRÍGUEZ, Juan Luis. 2002. El indigenismo en la Tarahumara. Identidad, comunidad, relaciones interétnicas y desarrollo en la Sierra de Chihuahua. México: INI-CONACULTA-INAH.

. 2008a. "Recursos naturales, políticas ambientales y pueblos indígenas en la Tarahumara". en J. L. Sariego Rodríguez (ed.), La Sierra Tarahumara: travesías y pensares. México: ENAH-INAH-CONACULTA. pp. 69-110. . 2008b "La nueva fiebre de los metales en el norte de México: Capitales, territories y conflictos". en J. L. Sariego (comp.), El norte de México: entre fronteras. México: Instituto Nacional de Antropología e Historia. SECRETARIA DE INNOVACIÓN Y DESARROLLO ECONÓMICO, GOBIERNO DEL ESTADO DE CHIHUAHUA. 2018. Prontuario Estadístico. Centro de información Económica y Social, Chihuahua, México. Disponible en: http://www. chihuahua.com.mx/public/uploads/ pages/17/Prontuario $\% 20$ marzo $\% 20$ 2018.pdf [consultado 26/10/2019].

SILVICULTORES UNIDOS DE BALLEZA, A.C. 2018. Actualización del Estudio de la Cuenca de Abasto de la Región Sur del estado de Chihuahua, Mex. México: SEMARNAT-CONAFOR.

STENGERS, Isabelle. 2005. "The Cosmopolitical Proposal". In: B. Latour \& P. Weibel (eds.), Making Things Public: Atmospheres of Democracy. Cambridge, MA: MIT Press. pp. 994-1003.

. 2010. Cosmopolitics I, Traducido por Robert Bononno, Minneapolis-London, University of Minnesota Press. . 2011. Cosmopolitics II, Traducido por Robert Bononno, Minneapolis-London, University of Minnesota Press.

. 2014. "Gaia, the Urgency to Think (and Feel)". Os mil nomes da Gaia.
Antropoceno à Idade da Terra, Brasil. Disponible en: https://osmilnomesdegaia.files.wordpress.com/2014/11/ isabelle-stengers.pdf [consultado 26/10/2019]

. 2015. No tempo das catrastofes. Resistir à barbarie que se aproxima. Brasil: Cosac Naify.

STRATHERN, M. 2006 [1988]., O Genero Da Dádiva: Problemas Com As Mulheres E Problemas Com A Sociedade Na Melanésía São Paulo, Editora Da Universidade Estadual Do Campinas. SUBRAMANIAN, Meera. 21-05-2019. "Anthropocene now: influential panel votes to recognize Earth's new epoch". Nature. Disponible en: https:// www.nature.com/articles/d41586-01901641-5 [consultado 26/10/2019].

SVAMPA, Maristella. 2019. "El Antropoceno como diagnóstico y paradigma. Lecturas globales desde el Sur" Utopía y Praxis Latinoamericana, vol. 24, núm. 84, Universidad del Zulia, Venezuela.

THORD-GRAY, Ivon. 1955. Tarahumara-English. English-Tarahumara. Dictionary. University of Miami Press, Florida.

TOLA, Florencia, Antonela dos SANTOS, Juan Pablo RESTREPO, Gabriel RODRIGUES LOPES, Sonia SARRA, Agustina De CHAZAL y Maximiliano VARELA. 2019. "Entre el futuro que ya llegó y el pasado que nunca pasó: diplomacias chaqueñas en el Antropoceno", Mana 25(3): 809-836, Brasil.

TRISCHLER, Helmuth. 2017. "El Antropoceno, zun concepto geológico o cultural, o ambos?". Desacatos, 54: 40-57. TSING, Anna Lowenhaupt. 2005. Friction. An Ethnography of Global Connection. Princeton: Princeton University Press.

ULLOA, Astrid. 2007. "Implicaciones ambientales y culturales del cambio climático para los pueblos indígenas". 
Seminario internacional Mujeres Indígenas y cambio climático. Bogotá: Universidad Nacional de Colombia-UNODC-Fundación natura.

. 2017. "Dinámicas ambientales y extractivas en el siglo XXI: ¿̇es la época del Antropoceno o del Capitaloceno en Latinoamérica?". Desacatos, 54:58-73.

UNESCO, ISSC, CLACSO. 2013. Informe Mundial Sobre Ciencias Sociales. Cambios Ambientales Globales. Edicios UNESCO.

VALIÑAS, Leopoldo. 2001. "Lengua, dialectos e identidad étnica en la Sierra Tarahumara". en C. Molinari y E. Porras (coords.), Identidad y Cultura en la Sierra Tarahumara. México: Instituto Nacional de Antropología e Historia. pp.105-125.

VELASCO, Pedro de. 1987. Danzar o morir. Religión y resistencia a la dominación en la cultura tarahumar, Centro de Reflexión Teológica, México.

VIVEIROS DE CASTRO, Eduardo. 2010. Metafísicas caníbales. Líneas de antropología postestructural. Argentina: Katz.

WYNDHAM, Felice. 2009. "Spheres Of Relations, Lines Of Interaction: Subtle Ecologies Of The Rarámuri Landscape In Northern Mexico". Journal of Ethnobiology, 29(2): 271-295.

\section{Recursos electrónicos}

ALIANZA SIERRA MADRE. 2014. Alianza Sierra Madre. Disponible en: http:// alianzasierramadre.org/es/

THE NATURE CONSERVANCY. 2018. Alianza México para la Reducción de Emissiones de carbono por Deforestación y Degradación, REDD+. Disponible en: http://www.alianza-mredd.org/ CONTEC. 2017. Consultoría Técnica Comunitaria A.C. Disponible en: http://kwira.org/

DEFENSA TARAHUMARA. 2012. Red en defensa de territorios indígenas de la Sierra Tarahumara. Disponible en: http://es.defensatarahumara. org/? $p=459$
SCHMIDT, Jeremy. 2012. THE ANTHROPO.SCENE. Making up the 'world' with what we have on hand. Disponible en: https://jeremyjschmidt.com/

TARAHUMARA SUSTENTABLE. 2016 "Visión rarámuri sobre gobernanza ambiental" [video]. Disponible en: https://www.youtube.com/ watch? $\mathrm{v}=\mathrm{mIGEkLVnmMU}$

TARAHUMARA SUSTENTABLE, 2019. Proyecto Tarahumara Sustentable. Disponible en: http://www.tarahumarasustentable.mx/ 


\section{CAMINOS RARÁMURI PARA SOSTENER O ACABAR EL MUNDO. TEORÍA ETNOGRÁFICA, CAMBIO CLIMÁTICO Y ANTROPOCENO}

\section{CAMINHOS RARÁMURI PARA SUSTENTAR OU ACABAR O MUNDO. TEORIA ETNOGRÁFICA, MUDANÇA CLIMÁTICA E ANTROPOCENO}

\section{Resumen}

El objetivo de este artículo es problematizar cómo las premisas y las implicaciones del cambio climático y del Antropoceno están presentes, de forma previa y paralela, en la teoría-práctica rarámuri, específicamente a través del concepto de caminar-caminos y de las acciones nativas dedicadas al "cuidado del entorno" y a "sostener el mundo". Dicha teoría etnográfica reconoce una multiplicidad de agentes internos y externos al kawí (montaña, sierra, mundo, la tierra, terruño), así como de vínculos que generan divergencias y fricciones inconmensurables $y$, en este sentido, es que puedo hablar de estrategias cosmopolíticas. Todo ello expresa que los rarámuri han reflexionado desde hace tiempo sobre el impacto de las acciones humanas en el entorno, ya sea cuidándolo o colaborando con el latente riesgo de que el mundo acabe, tal como está inscrito en sus mitos de origen. En términos rarámuri, los vínculos, sean individuales o colectivos, y las acciones concretas determinarán el mundo que se habitará, ya que seguir un camino específico -camino de los antepasados (anayáguari boé) o el camino otro (si'nú boé)-implica participar de flujos particulares de relaciones y de sustancias regenerativas|degenerativas.

Palabras clave: Rarámuri o Tarahumaras, Teoría Etnográfica, Caminar-Camino, Sostener el mundo, Cambio climático, Antropoceno.

\section{Resumo}

O objetivo deste artigo é problematizar como as premissas e as implicações da mudança climática e do Antropoceno estão presentes, de maneira prévia e paralela, na teoria-prática rarámuri, especificamente através do conceito de caminar-caminos e ações nativas dedicadas a "cuidar do meio ambiente" e "segurar o mundo". Essa teoria etnográfica reconhece uma multiplicidade de agentes internos e externos ao Kawí (montanhas, serrado, mundo, terra), bem como de vínculos que geram divergências e fricções incomensuráveis e, nesse sentido, que posso falar sobre estratégias cosmopolíticas. Tudo isso expressa que os Rarámuri há muito refletem sobre o impacto das ações humanas no meio ambiente, seja cuidando ou colaborando com o risco latente de que o mundo vai acabar, como está inscrito em seus mitos de origem. Em termos rarámuri, os vínculos, individuais ou coletivos, e as ações concretas determinarão o mundo que será habitado, pois seguir um caminho específico - o caminho dos antepassados (anayáguari boé) ou o outro caminho (si'nú boé) - implica participar de fluxos particulares de relacionamentos e substâncias e regenerativas | degenerativas. Palavras-chave: Rarámuri ou Tarahumaras, Teoria Etnográfica, Percursos pedestres, Sustentar o mundo, Mudança climática, Antropoceno. 


\title{
RARÁMURI PATHWAYS TO HOLD \\ OR TO END OF THE WORLD. \\ ETHNOGRAPHIC THEORY, CLIMATE \\ CHANGE AND ANTHROPOCENE
}

\begin{abstract}
This article aims to question how the premises and implications of climate change and of the Anthropocene are present, in a prior and parallel way, in Rarámuri theory-practice, specifically, through the concept of caminar-caminos and native actions dedicated to "caring for the environment" and "hold the world." This ethnographic theory recognizes a multiplicity of agents that are internal and external to the Kawí (mountain, mountains, world, land, homeland), as well as links that generate divergences and immeasurable frictions. In this sense, I can speak of cosmopolitical strategies. All of this demonstrates that the Rarámuri have long reflected on the impact of human actions on the environment, whether by taking care of it, or by collaborating with the latent risk that the world ends, as inscribed in their myths of origin. In Rarámuri terms, the links, whether individual or collective, and concrete actions will determine the world that will be inhabited, since following a specific path - be it the path of the ancestors (anayáguari boé) or the other path (si'nú boé) - implies participating in particular flows of regenerative|degenerative relationships and substances.

Keywords: Rarámuri or Tarahumaras, Ethnographic Theory, Caminar-caminos, Holding the World, Climate Change, Anthropocene
\end{abstract}

